\title{
The Extent of Employing the Active Learning Strategies in the Vocational Education Course in Jordan from the Perspective of Teachers and Students
}

\author{
Dr. Sameer Aowad Kassab Shdaifat. \\ Al- Balqa' Applied University (BAU) \\ Al - Huson \\ Head of the vocational education department \\ Assistant professor
}

\begin{abstract}
The present study aimed to identify extent of employing the active learning strategies in the vocational education course in Jordan from the perspective of teachers and students. The sample consists from 80 teachers who teach vocational education course. It also consists from 120 primary school students. Those teachers and students were selected from several public schools in Jordan. To meet the study's goals, the researcher developed a fourteen item questionnaire. This questionnaire was developed based on the questionnaire of Wondifraw \& Dorothy (2019). It was found that the extent of employing the active learning strategies in the vocational education course is high from the teachers' perspective. It was found that the extent of employing the active learning strategies in the vocational education course is moderate from the students' perspective. Several recommendations were proposed by the researcher. For instance, the researcher recommends increasing the extent of employing the active learning strategies in the vocational education course in public schools in Jordan. That can be ensured through providing those schools with the required tools that enable the teachers to employ the active learning strategies effectively. Keywords: Active learning strategies, vocational education course
\end{abstract}

DOI: $10.7176 / \mathrm{JEP} / 11-6-19$

Publication date: February $29^{\text {th }} 2020$

\section{Introduction:}

Scientific and technological developments play a significant role in developing people's lives in various areas. For instance, they made changes to the way of teaching students at schools. Teaching through the active learning strategies shall develop students' higher order thinking skills and increase their interaction inside the classroom. Employing a conventional learning strategy today isn't suitable. That is attributed to the emergence of technological developments. Teacher is one of the elements of the educational system. He/she affects the other elements of the educational system. He/she plays a significant role in education. His/her role during the $21^{\text {st }}$ century differs from his/her role during other centuries. To be specific, teacher today is not responsible for transmitting knowledge to students. In fact, he/she must facilitate the process of learning. The teacher must be a facilitator of knowledge because learning aims at promoting creativity, and developing one's skills including scientific thinking skills (Al-Jamal, 2017).

Modular teaching is useful for each student. It permits students to think for themselves. It provides much attention to each student and his/her abilities, and aspirations. It enriches each students' experiences. It enables teachers to deliver education of high quality (Wondifraw\& Dorothy, 2019). Shaaruddin\& Mohamad (2017) suggest that active learning has been receiving much attention by researchers. Fisher (2010) suggests that the traditional teaching approaches have many limitations. Green et al (2018) suggest that it has been proved that the active learning strategies are more effective than the other learning strategies. They suggest that the active learning strategies facilitate the learning process (Green et al, 2018).

Many studies suggest that the active learning strategies are more effective than the conventional learning strategies. For instance, through employing active learning strategies, positive educational outcomes can be reached and information retention can increase (Freeman et al. 2014).

Employing active learning strategies shall assist students in remembering about $70 \%-90 \%$ of the information they have learnt two weeks ago. The active learning strategies involve several types of activities, such as: holding group discussions, making presentations, and presenting simulation models. In contrast, students who are engaged in passive learning strategies retain about $10 \%-30 \%$ of the information they have learnt two weeks ago. The passive learning strategies: include: analyzing maps, and graphs (Shaaruddin\& Mohamad, 2017).

Jones \& Myers (1993) define active learning as: learning strategies that grant students the opportunities to express themselves, listen, write, read and observe things well. The active learning strategies involve problem solving activities, learning in small groups, presenting simulation models, role playing activities, and etc.. They require applying the things they have learnt in real life.

Through employing active learning strategies, the student shall learn by himself/herself. Through employing 
active learning strategies, students shall play a significant role in identifying their learning needs and the knowledge and experiences they must acquire. They shall identify the method of acquiring the required knowledge and experiences. They shall identify the method of utilizing such knowledge and experiences. They shall manage their own learning process by themselves. Thus, the latter strategies activate the role of learners in the learning process. They shall make learners motivated to learn (Glasgow, 1996).

Teachers must keep gaining knowledge and developing their skills. That is needed in the light of experiencing globalization. It is needed in the light of having many technological developments. In other words, teachers must seek developing themselves professionally to keep up with the developments (Sahagun \& Matriano, 2019).

\section{Statement of the Problem:}

The number of the teaching and learning strategies have been increasing. That is attributed to the emergence of many technological developments. Wondifraw\& Dorothy (2019) \& Alharbi \& Cuihong (2019) suggest that it's very useful to employ the active learning strategies. The researcher of the present study suggest that there are many challenges facing vocational education teachers in public schools in Jordan. Hence, the problem of the present study is represented in the following question:

(What is the extent of employing the active learning strategies in the vocational education course in Jordan?)

\section{The Study's Objectives and Questions:}

The present study aimed to identify the extent of employing the active learning strategies in the vocational education course in Jordan from the perspective of teachers and students. The study's questions are presented below

Q.1: What is the extent of employing the active learning strategies in the vocational education course in Jordan from the teachers' perspective?

Q.2: What is the extent of employing the active learning strategies in the vocational education course in Jordan from the students' perspective?

\section{The Study's Significance:}

The present study is significant due to the following reasons:

- The present study shed a light on very important learning strategies (i.e. the active learning strategies). Thus, the results of the present study shall participate in raising the quality level of the provided vocational education in Jordanian public schools

- The present study participates in promoting awareness among teachers about the significance of employing active learning strategies.

- The present study provides recommendations and suggestions that improve the way of employing the active learning strategies in the vocational education course in Jordan.

\section{Definition of terms:}

The study's terms are defined below

*Active learning strategies: They refer to a set of strategies that can meet the students' learning needs, and develop their critical thinking skills (Alharbi \& Cuihong, 2019, 49)

*Vocational education course: It refers to a course that aims at providing students with skills that they may need in various aspects of life. Such skills may be related to (housekeeping, hotels \& tourism, engineering, maintenance, agriculture, economy, environment, technology, healthcare, and public safety) (Mahasneh \& Al-Azmi, 2015).

\section{The study's limits:}

The study's limits are presented below:

*The spatial limits: The present study was conducted in several public primary schools in Jordan.

*The temporal limits: The present study was conducted during January and February of the year 2020.

*The human limits: The present study targets the students enrolled in the public primary schools in Jordan. It targets the vocational education teachers working in public primary schools in Jordan.

\section{Review of Previous Studies:}

The following studies were reviewed by the researcher of the present study. They are arranged from the latest ones to the oldest ones

Wondifraw\& Dorothy(2019)aimed to shed a light on modularized curriculum in Ethiopian higher education institutions. They aimed to shed a light on (active learning and continuous assessment). Three universities were selected. (308) undergraduate students and 144 instructors were sampled through using the simple stratified random sampling. It was found that that the instructional process in the modularized program is not effective as expected. It was found that the teaching-learning process was found to be teacher-centered. It was found that the 
teaching-learning process is based on the use of PowerPoint presentations. It was found that knowledge is provided to students through the spoon feeing method. It was also found that continuous assessment is carried out through frequent tests and quizzes.

Alharbi \& Cuihong (2019) aimed to explore the reality of using active learning strategies in math courses in primary schools. It was found that active learning positively affects students' academic pass rates and academic achievement level. It was found that active learning improves students' higher-order thinking skills and capability to analyze things.

Al Ruthia et al. (2019) aimed to identify the extent of employing active learning strategies in several healthcare education in various countries in the Middle East Countries. The questionnaire forms were sent to 2085 faculty members. However, 772 forms were retrieved and analyzed. $87 \%$ of the respondents use one active learning strategy. It was found that females use active learning strategies more than males. It was found that $54.30 \%$ of the female faculty members suggest that they employ active learning strategies in classroom. It was found that $41.30 \%$ of the male faculty members suggest that they employ active learning methods in classroom $(p=0.0005)$. It was found that public and private healthcare colleges share similar levels in terms of the extent of employing the active learning strategies.

Sahagun \& Matriano (2019) aimed to explore the reality of the continuing professional development (CPD) and their perceived impact on teachers in a public elementary school in Zambales. They employed descriptive cross-sectional and correlational research designs. They used a questionnaire, and conducted informal interview. They used the observation method for collecting data. The study's population consists from all of the elementary teachers in the selected district.222 teachers were sampled. It was found that most of the respondents don't engage much in continuing professional development (CPD) activities. It was found that the continuing professional development (CPD) activities positively affect career development. It was found that the CPD improves the teaching-learning process and enhances the learning outcomes.

Tharayilet al (2018) aimed to collect data through conducting interviews with 17 engineers in USA. They aimed to explore the way they use strategies for reducing students' resistance to active learning in their undergraduate engineering courses. It was found that the explanation and facilitation strategies aren't effective for reducing such resistance. Regarding the explanation strategies, they consist from the following aspects: (a) explaining the goal, (b) explaining the expectations from students in the course, and (c) explaining expectations from carrying out a specific activity.

Regarding the facilitation strategies, they consist from the following aspects: (a) approaching nonparticipants, (b) carrying out an encouraging demeanor, (c) grading students' participation, (d) walking around the room, (e) asking students to ask questions, (f) developing a specific routine, (g) designing activities that give students the opportunity to participate, and (h) using incremental steps.

Green et al. (2018) aimed to shed a light on the implementation of active learning strategies in various university courses. It was found that active learning strategies positively affect the instructors' self-confidence and students' scores. Shaaruddin\& Mohamad (2017) aimed to investigate the teaching efficiency when integrating active learning strategies. Data was obtained through analyzing documents. The latter researchers adopted a qualitative approach. It was found that the active learning strategies are effective strategies. For instance, the active learning strategies create a positive learning environment and improve the instructor-student interaction. They promote respect for others' opinions and make students become open minded. They improve students' communication skill. They increase students' engagement in the learning activities and encourage them to participate (Shaaruddin\& Mohamad, 2017).

Aljamal (2017) aimed to explore the effectiveness of a training program which is based on active learning strategies. He aimed to explore the effectiveness of this program in developing the creative teaching skills of the math teachers working in an elementary school. The study's population consists from math teachers who teach $5^{\text {th }}$ and $6^{\text {th }}$ grade students in public schools. The study's sample consists from (27) teachers. It was found that the proposed program is very effective and develops the creative teaching skills of math teachers.

Ashley et al. (2015) aimed to explore the impacts of the active learning strategies in comparison to the passive ones in high school. They aimed to explore the impact of those strategies on students' knowledge, motivation to learn and perceptions for the learning process. An experimental approach was adopted. It was found that employing active learning strategies shall improve students' knowledge, motivation to learn and perceptions for the learning process

Kamarulzaman et al. (2018) aimed to explore the impacts of the active learning strategies on students' attitudes towards English language. They adopted a descriptive quantitative approach. They used a questionnaire to collect data from 100 students who are enrolled in the Universiti Teknologi Petronas. SPSS was used for analyzing the collected data. It was found that students have positive attitudes towards English language and the use of active learning strategies. It was also found that the higher-order cognitive skills of students shall be developed through using active learning strategies. It was also found that the active learning strategies increases students' understanding of lessons. Such strategies facilitate the process of retrieving information. They serve as 
effective strategies for delivering information. They encourage students to participate in classroom.

Abdolrezapour (2019) aimed to explore the effectiveness of computer mediated active learning strategies in improving EFL learners' listening comprehension. The sample consists from 56 EFL learners. It was found that computer mediated active learning strategies are effective in improving EFL learners' listening comprehension. The latter strategies reduce the anxiety associated with learning. They raise students' motivation to learn.

Comments on the aforementioned studies and the difference between them and the present study:

The aforementioned studies suggest that employing active learning strategies is very useful in educational institutions in general and schools in particular. Employing these strategies in vocational education and scientific courses, such as math is useful. Some studies of the aforementioned studies used a questionnaire, such as the ones conducted in Wondifraw\& Dorothy (2019);Sahagun \&Matriano (2019) and Al Ruthia et al. (2019). Other studies conducted content analysis, such as the one conducted by: Ashley et al. (2015); and Alharbi and Cuihong (2019). There is a difference between the aforementioned studies in terms of the population. As for the present study, it differs from the other studies in terms of subject. To be specific, the present study aimed to identify the extent of employing the active learning strategies in the vocational education course in Jordan from the perspective of teachers and students.

\section{The Study's Approach:}

The researcher of the present study adopted a descriptive analytical approach. The latter approach is adopted by many researchers for offering readers a sensory description for things and items. It can be adopted to determine whether certain sensory attributes are deemed accepted or not. It may be adopted by researchers to explore variables and their dimensions and constituents (Lawless and Heymann, 1999).

\section{The Study's Population}

The study's population consists from all the vocational education teachers working in public schools in Jordan. It also consists from all the students enrolled in public primary schools in Jordan.

\section{The Study's Sample:}

A simple stratified random sampling was used to select a sample. The sample consists from 80 teachers who teach vocational education course. It also consists from 120 primary school students. Those teachers and students were selected from public primary schools in Jordan. Table (1) presents data about the number of respondents.

\section{Table (1): The number of the respondents}

\begin{tabular}{|c|c|c|c|}
\hline Sample & Males & Females & Total \\
\hline Vocational education teachers & 49 & 31 & 80 \\
\hline Primary school students (i.e. $10^{\text {th }}$ grade students) & 88 & 32 & 120 \\
\hline
\end{tabular}

$\mathbf{N}=\mathbf{2 0 0}$

The Study's Instrument:

The present study aimed to identify extent of employing the active learning strategies in the vocational education course in Jordan from the perspective of teachers and students. Therefore, the researcher developed a questionnaire based on the questionnaire of Wondifraw\& Dorothy (2019). The study's questionnaire adopts the five point Likert scale. This scale consists from five rating categories; strongly agree, agree, moderate, disagree, and strongly disagree

\section{Validity of the instrument:}

Validity of the instrument was measured through passing the instrument to two experts to provide their opinions. Those experts were asked to assess the questionnaire in terms of relevancy, language and clarity. They suggested that the questionnaire is free from language mistakes and clear. They suggested that the questionnaire's items are relevant to the study's goals.

\section{Reliability of the questionnaire:}

Toe measure the reliability of the questionnaire, the researcher calculated the Cronbach Alpha coefficient values. The total value of the Cronbach Alpha coefficient is 0.856 . This value indicates that the questionnaire is highly reliable

\section{Statistical analysis methods:}

To meet the study's goals, the SPSS program was used to analyze the collected data. The following statistical methods were used by the researcher for analyzing data:

- Frequencies and percentages were calculated to provide a description for the study's respondents. 
- Means, and standard deviations were calculated to identify the respondents' attitudes

- The Coronach Alpha coefficient values were calculated to measure the instrument's reliability

\section{Statistical criteria for classifying means:}

2.34 or above: High

1.67-2.34: Moderate

1.67 or lower: Low

\section{The study's results}

\section{Results related to the study's first question}

Q.1: What is the extent of employing the active learning strategies in the vocational education course in Jordan from the teachers' perspective?

To answer this question, means and standard deviations were calculated. Table (2) presents the results related to the first question:

Table (2): The extent of employing the active learning strategies in the vocational education course in Jordan from the teachers' perspective

\begin{tabular}{|c|c|c|c|c|c|}
\hline No. & Item & Std. & Mean & Rank & Level \\
\hline 6 & $\begin{array}{l}\text { I use various teaching strategies which meet the students' } \\
\text { learning needs }\end{array}$ & 0.95 & 3.96 & 1 & High \\
\hline 1 & $\begin{array}{l}\text { I check students' prior knowledge about thetopic before } \\
\text { discussing it }\end{array}$ & 0.98 & 3.95 & 2 & High \\
\hline 3 & I encourage students to ask questions and express their opinions & 0.90 & 3.91 & 3 & High \\
\hline 7 & $\begin{array}{l}\text { I serve as a facilitator of knowledge instead of using the spoon- } \\
\text { feeding method }\end{array}$ & 0.90 & 3.80 & 4 & High \\
\hline 5 & I motivate students to engage in the teaching-learning process & 0.97 & 3.78 & 5 & High \\
\hline 4 & I intentionally hold debates and discussion in the classroom & 0.97 & 3.77 & 6 & High \\
\hline \multirow[t]{2}{*}{2} & $\begin{array}{l}\text { I ask students to comment on comment on their colleagues' } \\
\text { answers }\end{array}$ & 0.85 & 3.74 & 7 & High \\
\hline & Total & 0.72 & 3.88 & & High \\
\hline
\end{tabular}

Based on table (2), the extent of employing the active learning strategies in the vocational education course in Jordan is high from the teachers' perspective. That is because the total mean is 3.88 which is high. The total standard deviation is 0.72 . The mean of statement (6) is 3.96 which is ranked first. The latter statement states the following: (I use various teaching strategies which meet the students' learning needs). The mean of statement (2) is ranked last. It is 3.74 which is high. The latter statement states the following: (I ask students to comment on comment on their colleagues' answers).

The latter result may be attributed to the significance of using this strategy. It may be attributed to the capability of vocational education teachers in public primary schools to employ this strategy. It may be attributed to the fact that teachers in Jordanian public schools receive training courses regularly. Such courses increases the performance level of teachers and enable them to employ teaching strategies.

The latter result is consistent with the results concluded by Shaaruddin\& Mohamad (2017) and Alharbi \& Cuihong (2019). It is inconsistent with the results concluded by Wondifraw\& Dorothy (2019).

\section{Results related to the second question}

Q.2: What is the extent of employing the active learning strategies in the vocational education course in Jordan from the students' perspective?

To answer this question, means and standard deviations were calculated. Table (3) presents the results related to the first question: 
Table (3): The extent of employing the active learning strategies in the vocational education course in Jordan from the students' perspective

\begin{tabular}{|r|l|r|r|r|r|}
\hline No. & Item & Std. & Mean & Rank & Level \\
\hline 3 & $\begin{array}{l}\text { The vocational education teacher encourages students to ask } \\
\text { questions and express their opinions }\end{array}$ & 0.91 & 3.66 & 1 & Moderate \\
\hline 2 & $\begin{array}{l}\text { The vocational education teachers ask students to comment on } \\
\text { comment on their colleagues' answers }\end{array}$ & 0.93 & 3.65 & 2 & Moderate \\
\hline 4 & $\begin{array}{l}\text { The vocational education teacher intentionally holds debates } \\
\text { and discussion in the classroom }\end{array}$ & 0.97 & 3.61 & 3 & Moderate \\
\hline 5 & $\begin{array}{l}\text { The vocational education teacher motivates students to engage } \\
\text { in the teaching-learning process }\end{array}$ & 0.96 & 3.58 & 4 & Moderate \\
\hline 6 & $\begin{array}{l}\text { The vocational education teacher uses various teaching } \\
\text { strategies which meet the students' learning needs }\end{array}$ & 0.91 & 3.55 & 5 & Moderate \\
\hline 1 & $\begin{array}{l}\text { The vocational education teacher checks students prior } \\
\text { knowledge about the topic before discussing it }\end{array}$ & 0.90 & 3.49 & 6 & Moderate \\
\hline 7 & $\begin{array}{l}\text { The vocational education teacher serves as a facilitator of } \\
\text { knowledge instead of using the spoon-feeding method }\end{array}$ & 0.93 & 3.44 & 7 & Moderate \\
\hline & \multicolumn{1}{|l|}{ Total } & 0.99 & 3.49 & & Moderate \\
\hline
\end{tabular}

Based on table (10), the extent of employing the active learning strategies in the vocational education course in Jordan is moderate from the students' perspective. That is because the total mean is 3.49 which is moderate. The total standard deviation is 0.99 . The mean of statement (3) is 3.66 which is ranked first. The latter statement states the following: (The vocational education teacher encourages students to ask questions and express their opinions).The mean of statement (7) is 3.44 which is ranked last. The latter statement states the following: (The vocational education teacher serves as a facilitator of knowledge instead of using the spoon-feeding method).The latter result is consistent with the results concluded by Shaaruddin\& Mohamad (2017).

\section{Conclusion}

It was found that the extent of employing the active learning strategies in the vocational education course in Jordan is high from the teachers' perspective. It was found that the extent of employing the active learning strategies in the vocational education course in Jordan is moderate from the students' perspective. In the light of these results, the researcher believes that vocational education teachers must be provided with training courses about active learning.

\section{Recommendations:}

In the light of the study's results, the researcher recommends:

Increasing the extent of employing the active learning strategies in the vocational education course in public schools in Jordan. That can be ensured through providing those schools with the required tools that enable the teachers to employ the active learning strategies effectively.

Holding training courses for vocational education teachers at public schools in Jordan about the way of employing the active learning strategies.

\section{References:}

Alharbi, M., \&Cuihong Yang (2019) Impact of Active Learning on Mathematical Achievement: an Empirical Study in Saudi Arabia Primary Schools. Journal of International Business Research and Marketing, vol. 4, issue 2, pp. 43-51.

AlRuthia, Y.,Alhawas, S., Alodaibi, F., Almutairi, L., Algasem, R., Alrabiah, H., Sales, I., Alsobayel H., \& Ghawaa, Y. (2019) The use of active learning strategies in healthcare colleges in the Middle East. BMC Medical Education volume 19, Article number: 143.

Green, L., McCormick, N., McDaniel, S., Rowell, G., \&Strayer, J. (2018) Implementing Active Learning Department Wide: A Course Community for a Culture Change. Journal of Statistics Education Volume 26, 2018 - Issue 3.

Ashley L. Mueller, Neil A. Knobloch, and Kathryn S. Orvis (2015) Exploring the Effects of Active Learning on High School Students' Outcomes and Teachers' Perceptions of Biotechnology and Genetics Instruction. Journal of Agricultural Education, 56(2), 138-152.

Sahagun, J., \&Matriano, E. (2019) Impacts of Continuing Professional Development (CPD) Activities among Elementary School Teachers. Institutional Multidisciplinary Research and Development Journal, Vol 2.

/Glasgow,N. (1996). Doing Science. San Francisco: Corwin Press 
Jones, B. \& Meyers, C (1993). promoting active learning strategies for the college classroom. San Francisco: Jossey Bass Inc.

ALjamal, S. (2017) The Effectiveness of a Training Program Based on Active Learning in Developing Creative Teaching Skills among Elementary Stage Mathematics Teachers. Master Thesis . The Islamic University of Gaza.

Mahasneh, Omar, and Al-Azmi, Alya (2015) The Effect of Using the Workshop Conversation Approach with the Five-Student Groups in Achievement of Tenth Grade Students in Prevocational Education. Journal of Educational Science Studies Vol 42. N 1.

Wondifraw Dejene\& Dorothy Chen (2019) The practice of modularized curriculum in higher education institution: Active learning and continuous assessment in focus, Cogent Education, 6:1, Research Article

Tharayil, Sneha., Maura Borrego., Michael Prince., Kevin A. Nguyen, Prateek Shekhar, Cynthia J. Finelli \& Cynthia Waters (2018) Strategies to mitigate student resistance to active learning. International Journal of STEM Education volume 5, Article number: 7.

Freeman, S, Eddy, SL, McDonough, M, Smith, MK, Okoraoa for, N, Jordt, H, Wenderoth, MP. (2014). Active learning increases student performance in science, engineering, and mathematics. Proceedings of the National Academy of Sciences, 111(23), 8410-8415.

Shaaruddin, J., \& Mohamad, M. (2017). Identifying the Effectiveness of Active Learning Strategies and Benefits in Curriculum and Pedagogy Course for Undergraduate TESL Students. Creative Education, 8, 2312-2324.

Lawless H.T., and Heymann H. (1999) Descriptive Analysis. In: Sensory Evaluation of Food. Food science text series. Springer, Boston, MA

Kamarulzaman, L.; Abdul Ghani, M and Daud, W. (2018). The Effect of Active Learning Strategies on Students' Attitudes towards English: A Study at Universiti Teknologi Petronas. Online Journal of Language, Communication, and Humanities, 1(2)

Abdolrezapour, P. (2019). Applying Computer-Mediated Active Learning Intervention to Improve L2 Listening Comprehension. Applied Research on English Language. 8(4).p.511-530.

Acknowledgement:

The researcher would like to thank Al- Balqa' Applied University (BAU) for providing him with much support. 